\title{
Carcinoma of Vagina in Women with Utero Vaginal Prolapse: A Review After Eight Years of Diagnosis
}

\section{Kavuriel Eliyas Karunakaran*}

Senior Lecturer, Department of Clinical Sciences, Faculty of Health-Care Sciences,

Eastern University and Hon. Consultant Obstetrician and Gynaecologist, Teaching

Hospital, Batticaloa, Sri Lanka

*Corresponding Author: Kavuriel Eliyas Karunakaran, Senior Lecturer, Department of Clinical Sciences, Faculty of Health-Care Sciences, Eastern University and Hon.

Consultant Obstetrician and Gynaecologist, Teaching Hospital, Batticaloa, Sri Lanka.
Received: April 12, 2021

Published: December 31, 2021

(C) All rights are reserved by Kavuriel Eliyas Karunakaran.

\section{Abstract}

This paper looks into a review of our experience on the woman surviving to date, over seven years of detection of primary vaginal carcinoma associated with utero vaginal prolapse, despite she had a second lesion. Such cancer although rare, is continuing to get reported and thus warranting a Primary Health-Care approach on post-menopausal women for prevention or early detection.

Keywords: Carcinoma of Vagina; Utero Vaginal Prolapse; Survival

\section{Case Report Review}

We, from the University Obstetrics and Gynaecology unit of Faculty of Health-Care Sciences, Eastern University, Sri Lanka at Teaching Hospital, Batticaloa, Sri Lanka reported two cases of Squamous cell Carcinoma of vagina occurred on patients with Utero Vaginal Prolapse [1]. Both women were under seventy years of age [Mrs. J N 56 years, Mrs. PK, 64 years] presented with prolapse and ulcer and undergone Vaginal Hysterectomy and anterior colporrhaphy. The first case [Mrs JN] had the prolapse for five years. There was no adequate vaginal tissue for clear resection. Nevertheless, she recovered from the surgery and the surgical wound had healed. She declined to receive further treatment and appeared three month later with widespread malignancy involving the entire vagina. She died within few days.

The second case of ours [Mrs. PK] had surgery done in 2013. The surgery had clear dissection of vagina from the malignant ulcer. She continued to receive adjuvant therapy. She survived for five years when presented with a secondary lesion in 2018. The lesion was resected. She is still living and attending the clinic in February 2021.

\section{Discussion and Conclusion}

Primary vaginal cancer is a rare disease and continues to get reported. Although rare, it contributes to the female cancer morbidity and mortality. This statement becomes significant due to the preventive nature of this disease, as the common risk factor is the sexually transmittable Human Papilloma Virus which has its main associations with development of Carcinoma of cervix. Further, as reported in the literature chances of developing malignant lesion in the prolapsed vagina are of significance and it was reported that $13.6 \%$ to $16.3 \%$ of total vaginal cancer coexist with utero vaginal prolapse [2]. This is especially so as the reported cases of vaginal carcinoma had occurred in patients came under our care with utero vaginal prolapse (UVP).

Pelvic floor dysfunction associates with UVP. In an analysis done among the reported literature in 16 developing countries, the mean 
prevalence of UVP is $19.7 \%$, with the range of 3.4 to 56.4 percent [3]. Similar trend is seen in studies reported from the developed countries, and a study reported that the rate of uterine prolapse in the United States was $14.2 \%$ [4]. Risk factors for the prolapse in developing countries are similar to those in more affluent countries particularly increased age and parity. Further, many literatures show the occurrence of this type of cancer at or after seventy years of age [5-7]. However, in our study cancer occurred at younger age.

Thus utero vaginal prolapse is a universal condition and thus the risk of developing vaginal cancer. The prolapse, when longstanding, has a high tendency in developing decubitus ulcer. The prolapse leads to venous congestion and resultant oedema. The vaginal tissue gets stretched and leads to a decrease in tissue strength. Reduction in the hormone Oestrogen in Menopause too contribute to the reduction of tissue strength. Friction between the prolapsed organ and patients' cloth too increase the likelihood of tissue friability [8]. All these factors contribute to the ulceration of UVP. Continuous tissue irritation will lead to neoplastic changes in the vaginal tissue and increases the chances of developing the cancer. Treatment is always challenging, and options include radiotherapy, surgery, or palliative treatment [9]. It should also be emphasized that Pelvic organ prolapse and carcinoma of the cervix are common entities, but their association is rare. In more than $60 \%$ of the cases, the uterine prolapse is present for at least 10 years [10]. This indicates the risk the women with UVP have, with regard to this common yet preventable cancer.

Utero Vaginal Prolapse at its initial stages produces symptoms of low back pain, discomfort and associated urinary symptoms. When accustomed to the prolapse, women tend to live with, until the development of significant complication such as ulcer, bleeding/discharge, irreducible nature and urinary incontinence. By then, the woman is with advanced age and with other co-morbidities. Lack of family support, Socio economic issues, negligence of symptoms are some of the factors which contribute to delay in seeking care. Poor nutritional status and poor ability in maintaining hygiene also attributable to worsen her health status. Thus, females, especially in postmenopausal age need to be taken care of with regard to the reproductive organs' health. These are women cohort who contribute immensely to the family welfare and generation build-up. The organ prolapse becomes worse due to the manual work they performed which contribute to the economy at the family and national level. Their role as grand-parent is beyond measure. Therefore, the health sector has the responsibility to look after such women with UVP to institute appropriate remedy.

Therefore, screening post-menopausal women should become a Primary Health-Care concern. Those women with UVP should be offered appropriate treatment to prevent the longstanding illness and thus prevent developing carcinoma of vagina. Insertion of pessary may be ideal to women at a younger age group in order to retain uterine function. It may be a feasible option for women motivated enough to attend the healthcare regularly for pessary care. Sacro colpopexy is also suggested surgical procedure to patients with UVP. Nevertheless, its usefulness in postmenopausal women need to be explored.

This leads to the next option in the management of UVP: the surgery 'vaginal hysterectomy and repair'. In our case both patients had undergone vaginal hysterectomy and anterior colporrhaphy. Both of them recovered from surgery with healed surgical wound (1). This indicates the healing nature of the vaginal tissue and at the same time remedy for the prolapse. During surgery vagina is fixed with utero sacral ligaments thus prevents the vault prolapse. Therefore, vaginal hysterectomy and repair should be considered for postmenopausal women developing UVP before it becomes longstanding enough to cause complications including the rare occurrence of vaginal cancer.

Let me reproduce the same conclusion in my original article (1): 'Although rare, impact of vaginal cancer in women's health should not be underestimated. This is especially so to women with utero vaginal prolapse who had a higher tendency in developing squamous cell carcinoma of vagina. Almost all reported cases have longstanding prolapse. This indicates that, especially postmenopausal women, when present with utero vaginal prolapse, they are offered vaginal hysterectomy and repair. If the pessary is preferred, vaginal cytology too should be performed on regular basis since the precursor lesion VAIN could be detected.

\section{Bibliography}

1. Karunakaran KE. "Carcinoma of Vagina in Women with Utero Vaginal Prolapse: Presentation of Two Cases and the Review of Literature (2018)". Womens Health Science Journal 2.3 (2018): 000119. 
2. Fedus T., et al. "Primary vaginal squamous cell carcinoma with bladder involvement in uterine prolapsed patient: Case report". Medicine (Baltimore) 96.50 (2017): e8993.

3. Walker GJA and Gunasekara P. "Pelvic organ prolapse and incontinence in developing countries: Review of prevalence and risk factors". International Journal of Urogynecology 22.2 (2011): 127-135.

4. Hendrix SL., et al. "Pelvic organ prolapse in the Women's Health Initiative: gravity and gravidity". American Journal of Obstetrics and Gynecology 186.6 (2002): 1160-1166.

5. Ishibashi N., et al. "Radiation therapy for vaginal cancer in complete uterine prolapse with intrauterine adhesion: a case report". BMC Women's Health 19 (2019): 69.

6. Yagi A., et al. "Descriptive epidemiological study of vaginal cancer using data from the Osaka Japan population-based cancer registry: Long-term analysis from a clinical viewpoint". Medicine (Baltimore) 96.32 (2017): e7751.

7. Sheikh NK., et al. "Vaginal Carcinoma with Third-Degree Uterine Prolapse". International Journal of Applied and Basic Medical Research 9.4 (2019): 246-247.

8. Isikhuemen ME., et al. "Decubitus Ulcers among Women with Utero-vaginal Prolapse”. Journal of Women's Health Care 7 (2018): 433.

9. Buda A., et al. "Locally-advanced vaginal cancer with complete utero-vaginal prolapse". International Journal of Gynecologic Cancer (2020).

10. Estevinho C., et al. "Complete pelvic organ prolapse associated with cervical cancer”. BMJ Case Report 14 (20212): e239706.

\section{Assets from publication with us}

- Prompt Acknowledgement after receiving the article

- Thorough Double blinded peer review

- Rapid Publication

- Issue of Publication Certificate

- High visibility of your Published work

Website: www.actascientific.com/

Submit Article: www.actascientific.com/submission.php

Email us: editor@actascientific.com

Contact us: +919182824667 